\title{
Studies on the Cellulose-Binding Domains Adsorption to Cellulose
}

\author{
Ricardo Pinto, Susana Moreira, Manuel Mota, and Miguel Gama* \\ Centro de Engenharia Biológica - CEB, Largo do Paço, Universidade do Minho, \\ 4710-057 Braga, Portugal
}

Received August 29, 2003. In Final Form: November 24, 2003

\begin{abstract}
Cellulose-binding domains (CBD) are modular peptides, present in many glycanases, which anchor these enzymes to the substrate. In this work, the effect of CBD adsorption on the surface properties of a model cellulose, Whatman CF 11, was studied. The methods applied ind ude inverse gas chromatography (IGC), ESCA, X-ray diffraction, and scanning el ectron microscopy (SE M). The CBD partition affinity (0.85 $\mathrm{L} / \mathrm{g}$ ) was cal culated from adsorption isotherms. However, true adsorption equilibrium does not exist, since CBDs are apparently irreversibly adsorbed to the fibers. Both IGC and ESCA showed that fibers with adsorbed CBD have a lower acidic character and al so a slightly higher affinity toward aliphatic mol ecules. This may however bea consequence of an increased surfacearea, a hypothesis that is supported by mi croscopic observations. The crystallinity index was not affected by CBD treatment.
\end{abstract}

\section{Introduction}

The cellulose degrading enzymes (cellulases) are constituted with threedomains: thecatalytic domain, a highly O-glycosylated linker region, and a carbohydrate-binding module (CBM). Several works have shown that the presence of CBM is essential for the enzyme binding to insoluble substrate and, consequently, for its efficient degradation. ${ }^{1-3}$ In the soluble substrates, the presence of the CBM does not affect the enzyme activity. 4,5 Deletion of the linker reduces the enzyme activity over insoluble cellulose, even if adsorption still occurs. ${ }^{6}$

According to the aminoacid sequence homology, CBMs are classified in more than 30 families, $^{7}$ the cellulose binding domains (CBD) being distributed in the first thirteen. All of theidentified fungi CBDs bel ong to F amily 1 and have between 36 and 40 amino acid residues. Even if the amino acid sequence in this family is highly conserved, significant differences havebeen found between several of these CBDs. For instance, Carrard and Linder ${ }^{8}$ reported that cellobiohydrolasel and II, from Trichoderma reesei, adsorb reversibly and irreversibly to bacterial microcrystalline cellulose (BMCC), respectively. These CBDs apparently adsorb to different sites on thesubstrate, according to Carrard et al.: ${ }^{9}$ a catalytic domain from a Clostridium thermocellum endoglucanase (CelD) was fused by these authors to different CBDs. After a certain period of BMCC hydrolysis with one of the hybrids, the

* Address correspondence to this author.

(1) Srisodsuk, M.; Lehtö, J .; Linder, M.; Margolles-Clark, E.; Reinikainen, T.; Teeri, T. T. J . Biotechnol. 1997, 57, 49-57.

(2) Palonen, H.; Tenkanen, M.; Linder, M. App. Environ. Microbiol. 1999, 65, 5229-5233.

(3) Limón, M. C.; Margolles-Clark, E.; Benítez, T.; Penttilä, M. FEMS Microbiol. Lett. 2001, 198, 57-63.

(4) Gilkes, N. R.; Warren, R. A. J .; Miller, R. C.; Kilburn, D. G. J Biol. Chem. 1988, 263, 10401-10407.

(5) Black, G. W.; Rixon, J . E.; Clarke, J . H.; Hazlewood, G. P.; Ferreira, L. M. A.; Bolam, D. N.; Gilbert, H. J . J . Biotech. 1997, 57, 59-69.

(6) Srisodsuk, M. Mode of action of Trichoderma reesei cellobiohydrolasel on crystallinecel lul ose; Technical Research Centre of Finland, VTT Publications, 1994; Vol. 188.

(7) Coutinho, P. M.; Henrissat, B. Carbohydrate-Active Enzymes (CAZY) server. http://afmb.cnrs-mrs.fr/ cazy/CAZY/index.html, 1999.

(8) Carrard, G.; Linder, M. Eur. J. Biochem. 1999, 262, 637-643.

(9) Carrard, G.; Koivula, A.; Söderlund, H.; Béguin, P. Proc. Natl. Acad. Sci. U.S.A. 2000, 97, 10342-10347. reaction is boosted adding another fused protein to the reaction mixture, but further addition of the samehybrid does not improve the reaction rate.

In previous works, ${ }^{10,11}$ we reported that the treatment of ol d paper board containers with CBDs may increase the pulp drainage rate and the paper resistance index, an effect that was attributed to surface/interfacial modifications. Similarly, Levy and colleagues showed that a CBD from Clostridium cell ul ovor ans improves the mechanical properties of Whatman paper sheets, an effect that was even more significant when a double CBD was used. ${ }^{12}$ It becomes obvious that it is important to understand the kind of modifications cellulose fibers suffers following CBDs adsorption. I ndeed, such effects may have technological significance, since it may be relevant in different fields where cellulases are used, such as paper and textile industries. Sofar, the effect of glycanases on thetreatment of wood and cotton fibers was analyzed always in the perspective of the hydrolytic phenomena. Although relatively low amounts of protein areused in thesetreatments (0.05-0.5 mg/gr fiber), paper and textile fibers have a relatively low surfacearea, and thus theadsor bed protein may have a significant effect on the fibers interaction. It is the purpose of this work to study the effect of CBD adsorption on the surface properties of the model cellulose Whatman CF 11. I nverse gas chromatography (IGC), ESCA, and adsorption isotherms were used to characterize this system.The IGC theory is well displayed in Schultz and Lavielle $\mathrm{e}^{13}$ and in a more recent review by Belgacem and Gandini. ${ }^{14}$

(10) Pala, H.; Lemos, M. A.; Mota, M.; Gama, F. M. EnzymeMicrob. Technol. 2001, 29, 274-279.

(11) Pala, H.; Pinto, R.; Mota, M.; Duarte, A. P.; Gama, F. M. In Application of Enzyme to Lignocellulosics; Mansfield, S., Saddler, I ., Eds.; ACS Symposium Series 855; American Chemical Society: Washington, DC, 2003; Chapter 7.

(12) Levy, I.; Nussunovitch, A.; Shpigel, E.; Shoseyov, O. Cellulose 2002, 9, 91-98.

(13) Schultz, J .; Lavielle, L. In I nverse Gas Chromatography; Lloyd, D. R., Ward, T. C., Scheiber, H. P., Pizaña, C. C., Eds.; ACS Symposium Series 391; American Chemical Society: Washington, DC, 1989; Chapter 14.

(14) Belgacem, M. N.; Gandini, A. In Interfacial Phenomena in Chromatography; Pefferkorn, E., Ed.; Marcel Dekker: New York, 1999; Chapter 2. 
Table 1. Characteristics of the IGC Probes ${ }^{a}$

\begin{tabular}{llccc}
\hline \multicolumn{1}{c}{ probes } & characteristics & $\gamma^{\mathrm{D}_{\mathrm{L}}}\left(\mathrm{mJ} / \mathrm{m}^{2}\right)$ & $\mathrm{a}\left(\AA^{2}\right)$ & $\mathrm{T}_{\text {eb. }}\left({ }^{\circ} \mathrm{C}\right)$ \\
\hline hexane & neutral & 18.4 & 51.1 & 68.7 \\
heptane & neutral & 20.3 & 57.0 & 98.5 \\
octane & neutral & 21.3 & 63.0 & 125.6 \\
decane & neutral & 23.4 & 75.0 & 174.1 \\
chloroform & acidic & 25.9 & 44.0 & 61.1 \\
THF & basic & 22.5 & 45.0 & 65.0 \\
diethyl ether & basic & 15.0 & 47.0 & 34.5 \\
acetone & amphoteric & 16.5 & 42.5 & 56.0 \\
ethyl acetate & amphoteric & 19.6 & 48.0 & 77.1
\end{tabular}

a According to Belgacem and Gandini, ${ }^{14}$ Belgacem et al., ${ }^{16}$ and Liu and Rials. ${ }^{17}$

\section{Experimental Section}

Materials. Whatman CF 11 (lote cat. $n^{\circ} 4021050$ ) cellulose fibers were used. CBDs were obtained by the method described in Lemos et al. ${ }^{15}$ The probes used for inverse chromatography were n-hexane, n-heptane, n-octane, and n-decane, chloroform, tetrahydrofuran (THF), diethyl ether, acetone, and ethyl acetate; all chemicals were of the highest purity available.

ESCA, X-ray Diffraction, and Scanning Electron Microscopy (SE M). Suspensions of Whatman CF 11 were prepared by mixing $10 \mu \mathrm{g}$ of CBD, per milligram of fiber, in $1 \mathrm{~mL}$ of sodium acetate buffer ( $50 \mathrm{mM}$, pH 5.0). Blanks were prepared similarly, but without CBDs. The incubation was carried out in a thermostatic bath at $50^{\circ} \mathrm{C}$, with agitation, for $12 \mathrm{~h}$ (SEM) and 5 days (ESCA and X-ray diffraction). Afterward, the fibers were centrifuged at $10000 \mathrm{~g}$ for $10 \mathrm{~min}$, frozen at $-80{ }^{\circ} \mathrm{C}$, and lyophilized.

The XPS spectra were obtained in a VG Scientific Escalab $200 \mathrm{~A}$, with Pisces data acquisition control software. A nonmonochromaticX-ray source was used with an aluminum anode operating at $15 \mathrm{kV} / 300 \mathrm{~W}$; for the detailed spectra the analyzer was operated with passageenergy of $20 \mathrm{eV}$. TheX-ray diffraction was obtained using a diffractometer (Philips PW-1710) with an automatic divergenceslit; a Cu anodewith a wavelength of 0.154 $\mathrm{nm}$ was used, and the spectra were obtained at $30 \mathrm{~mA}$ and 40 $\mathrm{kV}$. For the SEM observation, the fibers were coated with gold particles (Fisons Instruments Polaron SC502 Sputter Coater) and examined in a Leica Cambridge S360 microscope.

CBD Affinity and Binding Reversibility. Suspensions of Whatman CF 11 fibers, with a concentration of $10 \mathrm{mg}$ per $\mathrm{mL}$ of sodiumacetate buffer ( $50 \mathrm{mM}, \mathrm{pH} 5.0)$, in the presence of different CBD concentrations $\left(\mathrm{CBD}_{\text {Inicial }}\right)$, were incubated for $16 \mathrm{~h}$ at $5^{\circ} \mathrm{C}$, with magnetic agitation. Afterward, the fibers were centrifuged at $4000 \mathrm{rpm}$ for $10 \mathrm{~min}$ and the CBD concentration in the supernatant (CBDunbound) was measured in a J asco FP6200 spectrofluorimeter, operated at an emission and excitation wavelengths of 341 and $275 \mathrm{~nm}$, respectively. The apparatus was calibrated using CBD solutions with concentration determined using the BCA protein assay, from Pierce. The bound CBD was calculated using the following equation:

$$
\mathrm{CBD}_{\text {Bound }}=\frac{\left[\mathrm{CBD}_{\text {Initial }}\right]-\left[\mathrm{CBD}_{\text {Unbound }}\right]}{\mathrm{m}_{\mathrm{CF} 11}} \cdot \mathrm{V}_{\mathrm{R}}\left(u \mathrm{~mol}_{\mathrm{CBD}} / \mathrm{g}_{\mathrm{CF} 11}\right)
$$

where $V_{R}(L)$ corresponds to the volume of buffer used and $\mathrm{m}_{\mathrm{CF} 11}(\mathrm{~g})$ to the fibers mass.

Desorption assays were conducted to study the reversibility of the CBD-cellulose interaction. A CBD solution with a concentration of $35.9 \mu \mathrm{M}$ was all owed to equilibrate with CF 11 fibers for $16 \mathrm{~h}$ (to reach the equilibrium); the suspension was then diluted by 3-fold and left in contact for different periods of time, from 1 to $32 \mathrm{~h}$. The CBDs concentrations in thesupernatant were quantified as described previously.

Chromatography. The measurement of the retention volumes of the several probe molecules (Table 1) was carried out using Chrompak CP9001 chromatograph, equipped with a flame ionization detector (FID). Theseveral samples of cellul osic fibers to be analyzed were packed in a stainless steel column

(15) Lemos, M. A.; Teixeira, J . A.; Mota, M.; Gama, F. M. Biotechnol. Lett. 2000, 22, 703-707.
Table 2. Results of the XPS Analysis

\begin{tabular}{|c|c|c|c|c|c|}
\hline & \multirow[b]{2}{*}{ peaks } & \multicolumn{2}{|c|}{ CF 11 with CBD } & \multicolumn{2}{|c|}{ CF 11 without CBD } \\
\hline & & $\begin{array}{l}\text { binding } \\
\text { energy } \\
(\mathrm{eV})\end{array}$ & $\%$ area & $\begin{array}{c}\text { binding } \\
\text { energy } \\
(\mathrm{eV})\end{array}$ & $\%$ area \\
\hline \multirow[t]{3}{*}{ carbon 1s } & $C_{1}$ & 285.0 & 18.3 & 285.1 & 13.0 \\
\hline & $\mathrm{C}_{2}$ & 286.7 & 61.3 & 286.7 & 68.9 \\
\hline & $C_{3}$ & 288.4 & 20.4 & 288.4 & 18.1 \\
\hline \multirow[t]{2}{*}{ oxygen 1s } & $\mathrm{O}_{1}$ & 532.8 & 20.2 & 532.9 & 17.9 \\
\hline & $\mathrm{O}_{2}$ & 533.1 & 79.8 & 533.1 & 82.1 \\
\hline \multirow[t]{5}{*}{ nitrogen $1 \mathrm{~s}$} & $\mathrm{~N}_{1}$ & 400.2 & 94.2 & 400.0 & 64.5 \\
\hline & $\mathrm{N}_{2}$ & 402.3 & 5.8 & 402.9 & 35.5 \\
\hline & $\mathrm{O} / \mathrm{C}$ & 0.636 & & 0.661 & \\
\hline & $\mathrm{N} / \mathrm{C}$ & 0.021 & & 0.009 & \\
\hline & $\mathrm{C}_{2} /\left(\mathrm{C}_{1}+\mathrm{C}_{3}\right)$ & 1.58 & & 2.21 & \\
\hline
\end{tabular}

(Chrompack cat. $\left.\mathrm{n}^{\circ} \mathrm{CP} 99911 \mathrm{C}\right)$, one meter long and with $4 \mathrm{~mm}$ of internal diameter.

The Whatman CF 11 fibers were washed in $25 \mathrm{~mL}$ of acetate buffer $\left(50 \mathrm{mM}\right.$, pH5.0) per gram of fiber for $30 \mathrm{~min}$ at $50{ }^{\circ} \mathrm{C}$, with magnetic agitation. These fibers were used as blank. For the CBD treated cellul osethesame procedurewas applied, but using acetate buffer with a CBD concentration of $10 \mathrm{mg}$ per gram of fibers. Afterward, the fibers were centrifuged at $4000 \mathrm{rpm}$ for 2 min, washed with the same volume of distilled water, and again centrifuged. The fibers were then Iyophilized. Replicates were prepared using both the blank and CBD-treated fibers. Theexact mass of fibers in the column was weighed (about $6 \mathrm{~g}$ in each column).

The flow rate of the carrier gas (helium) was adjusted to 11$12 \mathrm{~mL} / \mathrm{min}$, using a soap bubble flowmeter. Both columns were conditioned, first for $2 \mathrm{~h}$ at $105^{\circ} \mathrm{C}$, then by applying temperature gradients from 35 to $70{ }^{\circ} \mathrm{C}$, with a step of $3{ }^{\circ} \mathrm{C} /$ minute, for $12 \mathrm{~h}$. The retention data were collected for several probes at $35^{\circ} \mathrm{C}$, $42^{\circ} \mathrm{C}$, and $50^{\circ} \mathrm{C}$. A Hamilton Gastight $1750 \mathrm{SL}$ syringe was used to inject a $50 \mu \mathrm{L}$ volume of each probe, mixed with the noninteractive marker (methane). A minimum concentration of the probes was used, to keep the infinite dilution assumption true. At least four analyses were carried out with each probe at each temperature.

\section{Results and Discussion}

ESCA. Comparing the CBDs treated fibers with the respective controls, the more obvious difference in the ESCA spectra (Figure 1, Table 2) is the $\mathrm{N}_{1}$ peak area. The relative proportion of this peak recorded at $400.0 \mathrm{eV}$ increases from 64.5 to $94.2 \%$ following the CBDs adsorption; the total area of nitrogen raises by more than 2 -fold. The $\mathrm{N}_{1}$ peak corresponds to nitrogen in a neutral amine $\left(-\mathrm{NH}_{2}\right)$ and peak $\mathrm{N}_{2}$ totheprotonated ammonium nitrogen $\left(-\mathrm{NH}_{3}{ }^{+}\right),{ }^{18,19}$ meaning that the adsorbed CBDs raised the concentration of neutral amines on the fibers surface, as expected. The presence of nitrogen on the control fibers is surprising, but not totally unexpected, since the fibers are obtained from wood and, being as large as shown in Figure 4, the extraction of noncellulosicmaterials is likely not to be complete.

Another spectrum modification is the relative increase of peak $C_{1}$ in the presence of the CBD. This peak corresponds to aliphatic $\mathrm{C}-\mathrm{C}$ and $\mathrm{C}-\mathrm{H}$ links that should not exist in purecellulose, thereforerevealing thepresence of impurities, probably lignin or extractives. The O/C values ( 0.661 and 0.636 , respectively, without and with CBD) arelower than thetheoretical valuefor purecellulose of $0.83 .{ }^{19} \mathrm{~A}$ similar result was described for other cellul osic

(16) Belgacem, M. N.; Czeremuszkin, G.; Saphiera, S. Cellulose1995, 2, 145-157.

(17) Liu, F. P.; Rials, T. G. Langmuir 1998, 14, 536-541.

(18) Matuana, L. M.; Balatinecz, J . J .; Park, C. B. Polym. Eng. Sci. 1998, 38, 765-773.

(19) Matuana, L. M.; Balatinecz, J . J .; Park, C. B.; Sodhi, R. N. S. Wood Sci. Technol. 1999, 33, 259-270. 

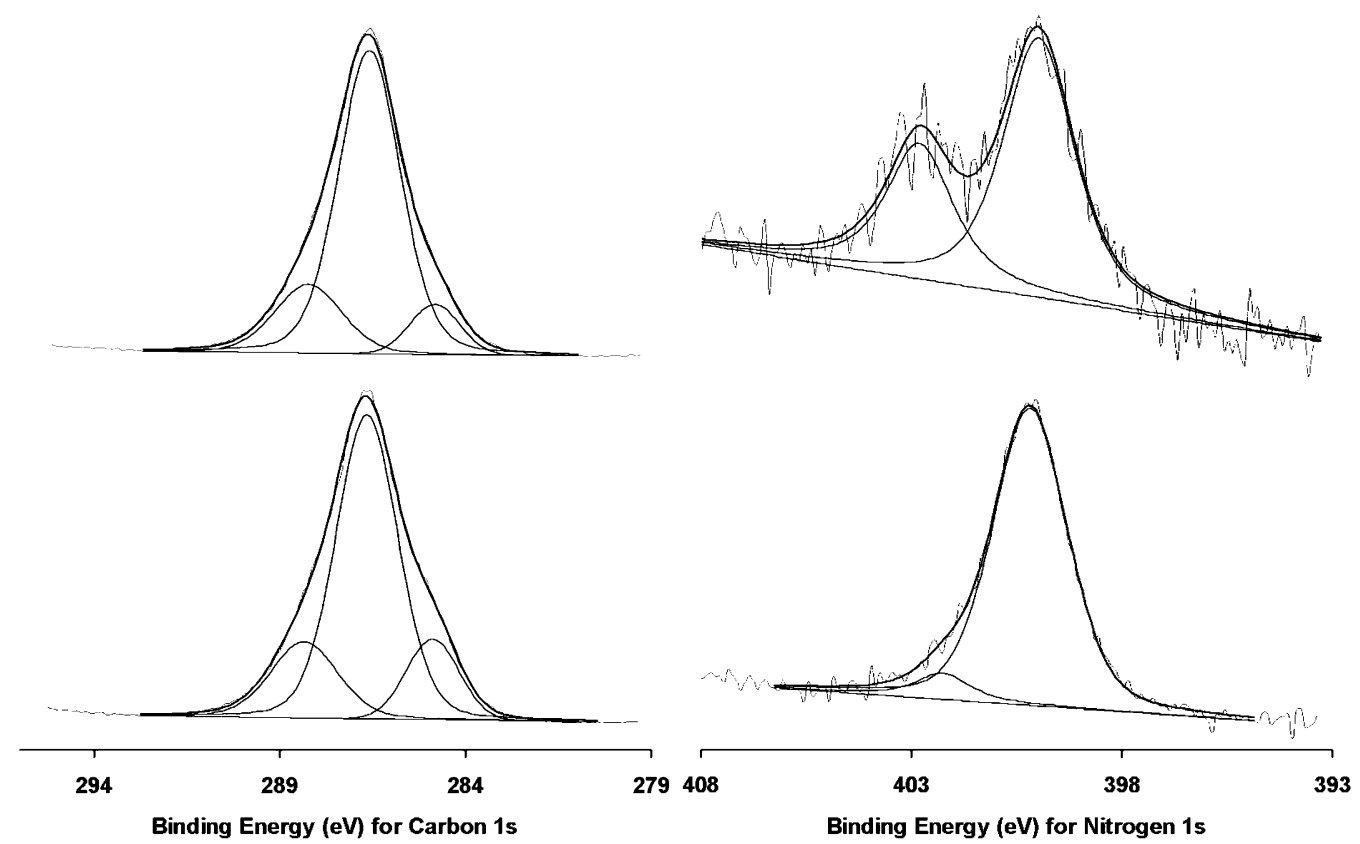

Figure 1. XPS spectra obtained for the CF 11 with (bottom) and without (top) CBD.

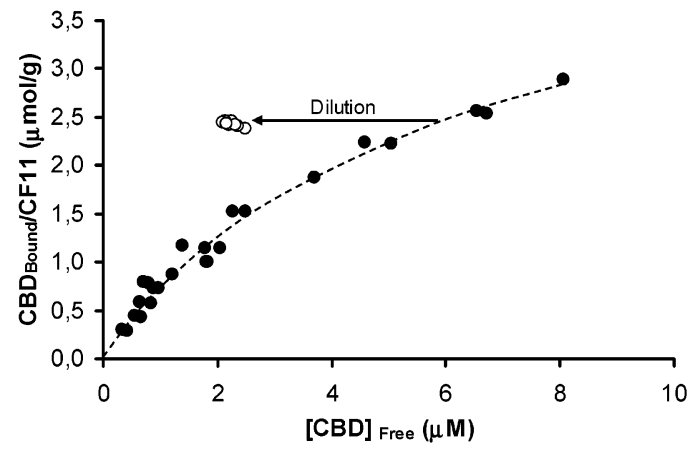

Figure 2. Adsorption isotherm of CBDs on CF11. The open circles correspond to the points obtained during the desorption assays, which were done for $1-32 \mathrm{~h}$.

materials such as C8002, a commercial product of Sigma Co. ${ }^{16}$ In that case, values of 0.66 and 0.80 were obtained, respectively, before and after extraction with acetone. Again, these results suggest that commercial celluloses are not totally pure. According to Shen et al., ${ }^{20}$ peak $\mathrm{C}_{2}$ relates to the fiber acidity, and peak $C_{1}$ and $C_{3}$ to its basicity. Thus, the ratio of $C_{2} /\left(C_{1}+C_{3}\right)$ may provide a measure of therelativeacid-base character of thefibers. According to the results, the presence of CBD reduces that value (Table 2) and thus the fibers acidity.

CBD Affinity and Binding Reversibility. The adsorption isotherm at $5^{\circ} \mathrm{C}$, obtained using $\mathrm{CBD}$ solutions with initial concentrations between 5.3 and $42.6 \mu \mathrm{M}$, is presented in Figure 2. The partition coefficient of $0.85 \mathrm{~L} / \mathrm{g}$ was calculated from theinitial sl opeof theisotherm. Linder and Teeri ${ }^{21}$ obtained a value of $4.9 \mathrm{~L} / \mathrm{g}$ for the adsorption of cell obiohydrolase I CBD to BMCC, at $5^{\circ} \mathrm{C}$, and Palonen et al. $^{2}$ of 2.7 and $1.2 \mathrm{~L} / \mathrm{g}$, respectively, for the CBDs of cellobiohydrolasel and II. The much higher surface area of BMCC, as compared to CF 11, may explain the differences between these values and the one obtained in this work. As shown in Figure2, the equilibrium reached after

(20) Shen, Q.; Mikkola, P.; Rosenholm, J . B. Colloids Surf., A 1998, 145, 235-241.

(21) Linder, M.; Teeri, T. T. Proc. Natl. Acad. Sci. U.S.A. 1996, 93, $12251-12255$.
$16 \mathrm{~h}$ between the soluble CBDs and the adsorbed ones is not a trueequilibrium. I ndeed, it appears that most CBDs are irreversibly bound to the fibers, since dilution does not lead to desorption. This is unexpected because the CBDs used in this work whereproduced from Trichoderma reese cellulases. This cellulolytic system contains four major proteins: cellobiohydrolases I (60-70\%) and II (20\%) and endoglucanases I and II. ${ }^{6}$ Several adsorption studies ${ }^{8,21}$ carried out with the CBDs of CBHI and CBHII on BMCC (a crystalline cellul ose, as CF 11), showed that the first adsorb reversibly, and the second irreversibly. Being a mixture of CBDs, the peptides used in this work wereexpected toadsorb reversibly, at least partially, which seems not to be the case. The CBD-adsorption assays described by different authors areperformed with different kinds of fiber. This may originate the apparently contradictory behavior regarding the binding reversibility. In any case, this irreversi bility should not imply that the CBDs areimmobile on the cellulose surface. J ervis et al. ${ }^{22}$ studied the surfacediffusion of a CBD from Cellul omonas fimi, that showed irreversiblebinding toa microcrystalline cellulose, although morethan $70 \%$ of the bound mol ecules were mobile on the cellulose surface. This phenomenon should bea characteristic of most if not all CBDs, otherwise the cellulases would not efficiently hydrolyze cellulose.

IGC, Cristallinity, and SEM. The chromatographic peaks obtained with the n-alkanes are symmetrical, whereas for the polar probes a tail was observed for all temperatures, both with the treated and untreated cellulose. This phenomenon has been described as resulting from the surface energy heterogeneity of the active sites at the fibers surface. ${ }^{23}$ If a simple model with two energy sites surface (high and low) is considered, it is expected that the probemolecules would interact stronger with the high energy sites, producing a wider and flatter peak, and weakly with the low energy ones, generating a sharp and narrower peak. The sum of these two peaks will result in an asymmetrical one ${ }^{24}$ exhibiting a tail, as is observed in the present case.

(22) J ervis, E. J .; Haynes, C. A.; Kilburn, D. G. J . Biol. Chem. 1997, 272, 24016-24023.

(23) van Asten, A.; van Veenendaal, N.; Koster, S. J . Chromatogr. 2000, 888, 175-196. 
Table 3. Specific Retention Volumes $\left(\mathrm{V}_{\mathrm{N}}{ }^{\circ}, \mathrm{mL} / \mathrm{g}\right)$ of the $\mathrm{CF} 11$ with and without $\mathrm{CBD}$, with Their Respective Mean Error

\begin{tabular}{|c|c|c|c|c|c|c|}
\hline \multirow[b]{2}{*}{ probes } & \multicolumn{3}{|c|}{ CF 11 with $\mathrm{CBD}$} & \multicolumn{3}{|c|}{ CF 11 without CBD } \\
\hline & $35^{\circ} \mathrm{C}$ & $42^{\circ} \mathrm{C}$ & $50^{\circ} \mathrm{C}$ & $35^{\circ} \mathrm{C}$ & $42^{\circ} \mathrm{C}$ & $50^{\circ} \mathrm{C}$ \\
\hline n-hexane & $0.93 \pm 0.01$ & $0.68 \pm 0.01$ & $0.51 \pm 0.01$ & $0.84 \pm 0.01$ & $0.68 \pm 0.03$ & $0.47 \pm 0.02$ \\
\hline n-heptane & $2.90 \pm 0.01$ & $2.06 \pm 0.01$ & $1.44 \pm 0.01$ & $2.67 \pm 0.00$ & $1.94 \pm 0.03$ & $1.31 \pm 0.01$ \\
\hline n-octane & $8.94 \pm 0.02$ & $6.19 \pm 0.02$ & $4.13 \pm 0.04$ & $8.46 \pm 0.02$ & $5.73 \pm 0.02$ & $3.74 \pm 0.02$ \\
\hline n-decane & $89.6 \pm 0.4$ & $57.0 \pm 1.6$ & $34.1 \pm 0.7$ & $84.3 \pm 0.3$ & $52.4 \pm 0.3$ & $31.4 \pm 0.1$ \\
\hline chloroform & $1.98 \pm 0.01$ & $1.42 \pm 0.00$ & $0.99 \pm 0.02$ & $1.97 \pm 0.01$ & $1.40 \pm 0.01$ & $0.97 \pm 0.01$ \\
\hline THF & $13.4 \pm 0.4$ & $8.81 \pm 0.12$ & $5.32 \pm 0.20$ & $15.9 \pm 0.5$ & $10.6 \pm 0.2$ & $6.56 \pm 0.10$ \\
\hline diethyl ether & $3.01 \pm 0.00$ & $2.00 \pm 0.01$ & $1.30 \pm 0.01$ & $3.86 \pm 0.03$ & $2.55 \pm 0.02$ & $1.67 \pm 0.02$ \\
\hline acetone & $10.0 \pm 0.2$ & $6.86 \pm 0.06$ & $4.26 \pm 0.17$ & $15.6 \pm 0.3$ & $10.9 \pm 0.5$ & $7.25 \pm 0.19$ \\
\hline ethyl acetate & $20.7 \pm 0.3$ & $13.4 \pm 0.4$ & $8.31 \pm 0.42$ & $28.6 \pm 1.1$ & $19.7 \pm 0.4$ & $13.2 \pm 0.5$ \\
\hline
\end{tabular}

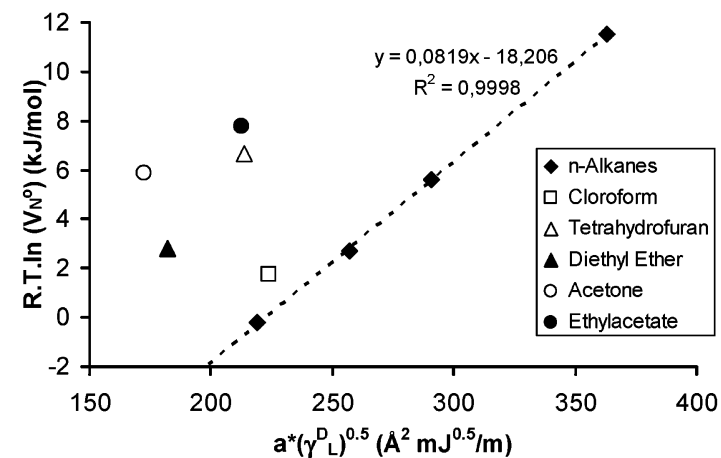

Figure 3. Surface free energy of adsorption vs $a \cdot\left(\gamma_{L}\right)^{0.5}$, for the CF 11 with $C B D$, obtained at $35^{\circ} \mathrm{C}$. The equation presented corresponds to the $\mathrm{n}$-alkanes reference line.

Thespecificretention volumes obtained with theseveral probes on the two columns are shown in Table 3. The values for the basic and amphoteric probes are reduced by 15 to $41 \%$, in the presence of adsorbed CBD. Theerrors obtained in the retention vol ume calculations are below $5 \%$, and thus thereferred reduction is significant. It seems then that the basicand amphoterichavel ower affinity for the fibers with adsorbed peptides. Another difference, al though of lower magnitude, can bedetected by comparing retention volumes: the neutral probes interact slightly stronger with thefibers with CBDs, suggesting that these reduce the surface polarity. This could be a consequence of the hydrophobic aminoacids present in theCBDs being exposed and freeto interact with the probes. Thoseamino acids would be expected to be interacting with the fibers, sincethey mediatetheadsorption process. However, there is experimental evidence (not shown) that these peptides aggregate in aqueous solution, and that would explain why some of the adsorbed binding domains may expose their hydrophobic flat surface.

Similar graphs to Figure 3 were obtained for the fibers without $\mathrm{CBD}$ and for each temperature. The reference lines for the n-alkanes have a good correlation coefficient (above 0.999). The dispersive component of the surface free energy $\left(\gamma^{D_{s}}\right)$-slope of the referenceline-is lower for higher temperature(Table4); several authors, 16,22,25,26 also studying cellulosic materials, reported the same trend, explained as a consequence of an expansion of the fibers with temperature. ${ }^{27} \mathrm{The} \gamma^{\mathrm{D}_{s}}$ valueis influenced by changes in the fibers structure, according to the work by Balard et al.$^{28}$ The values presented here are in good agreement with the ones reported by other authors. ${ }^{16,22,25,26}$

(24) Sun, C.: Berg, J . C. J . Chromatogr. A 2002, 969, 59-72.

(25) Tshabalala, M. A. J . Appl. Polym. Sci. 1997, 65, 1013-1020.

(26) Tshabalala, M. A.; Han, J . S. In Kenaf Properties, Processing and Products; Sellers, T.,J r., Reichert, N. A., Columbus, E. P., Fuller, M. J ., Williams, K., Eds; Mississippi State University: Starkville, MS, 1999; Chapter 12. 110.
Table 4. Values of the Dispersive Component of the Solid Surface $\left(\gamma^{\mathrm{D}} \mathrm{s}, \mathrm{mJ} / \mathrm{m}^{2}\right)$ for the Temperatures and the Two Methods Used

\begin{tabular}{clccc}
\hline method & & $35^{\circ} \mathrm{C}$ & $42{ }^{\circ} \mathrm{C}$ & $50{ }^{\circ} \mathrm{C}$ \\
\hline Schultz & CF 11 with CBD & $46.2 \pm 4.0$ & $43.4 \pm 3.5$ & $39.2 \pm 4.1$ \\
& CF11 without CBD & $47.0 \pm 4.1$ & $42.1 \pm 5.7$ & $39.4 \pm 4.3$ \\
Doris and & CF11 with CBD & $47.3 \pm 1.4$ & $44.9 \pm 0.5$ & $41.1 \pm 0.9$ \\
Gray & CF 11 without CBD & $48.0 \pm 0.5$ & $43.5 \pm 3.1$ & $41.3 \pm 1.6$
\end{tabular}

In the present work, the $\gamma^{\mathrm{D}} \mathrm{s}$ values obtained with the different columns are similar, considering the errors associated. As remarked already, there is a difference between the retention volumes of neutral probes obtained with the two columns. This difference may have been annulled by the calculations associated to the $\gamma^{\mathrm{D}_{\mathrm{s}}}$ value determination. Theanalysis of theretention volumevalues makes possible to detect differences that are no longer obvious when comparing the thermodynamic values cal culated after the compl ex treatment of theexperimental data. On the other hand, another explanation would be that CBDsincreasethefibers surfacearea. This possibility will be exploited later in the present work. In such case, the retention volume for surfaces with similar apolar properties would be larger for the sample with larger surface area (CBD-treated), although the dispersive energy would besimilar. Further study will focus on trying to demonstrate whether CBDs increase the dispersive character of the surfaces (by exposing hydrophobicamino acids) or whether an increase of surfacearea is the reason for these results. Since it has been reported two methods to calculate the value of $\gamma_{\mathrm{s}}$, one by authors Schultz and Lavielle ${ }^{13}$ and the other by Doris and Gray (as described by Bailey and Persaud ${ }^{29}$ ), they where both used in this work. The differences between the values obtained by those two methods may beexplained considering that thelatter assumes the alkanes area to be equal to the sum of as many $\mathrm{CH}_{2}$ groups as the number of carbons. I ndeed, each mol ecule has two methyl groups. Gutierrez et al. ${ }^{30}$ refers that the Schultz method should be morereliable, because it does not use just one value of either $\gamma_{L}^{D_{L}}$ or area.

Regarding $-\Delta \mathrm{G}_{\mathrm{SP}}$ (Table 5), the values obtained are higher for the amphoteric and basic probes. This result is expected becausethe cel lul ose fibers have $-\mathrm{OH}$ groups (responsible for the predominance of the $\mathrm{C}_{2}$ peak in the XPS spectrum), which areelectron acceptors, thus making thesurfaceacidic. ${ }^{31}$ Theadsorbed CBD significantly reduce theinteraction energies in theamphotericand basic probes for the three temperatures studied. This result may be

(28) Balard, H.; Aouadj, O.; Papirer, E. Langmuir 1997, 13, 12511255 156

(29) Bailey, R. A.; Persaud, K. C. Anal. Chim. Acta 1998, 363, 147-

(30) Gutierrez, M. C.; Rubio, J .; Rubio, F .; Oteo, J . L.J . Chromatogr., A 1999, 845, 53-66.

(31) Shen, W.; Filonanko, Y.; Truong, Y.; Parker, I. H.; Brack, N.; Pigram, P.; Liesegang, J . Colloids Surf., A 2000, 173, 117-126. 

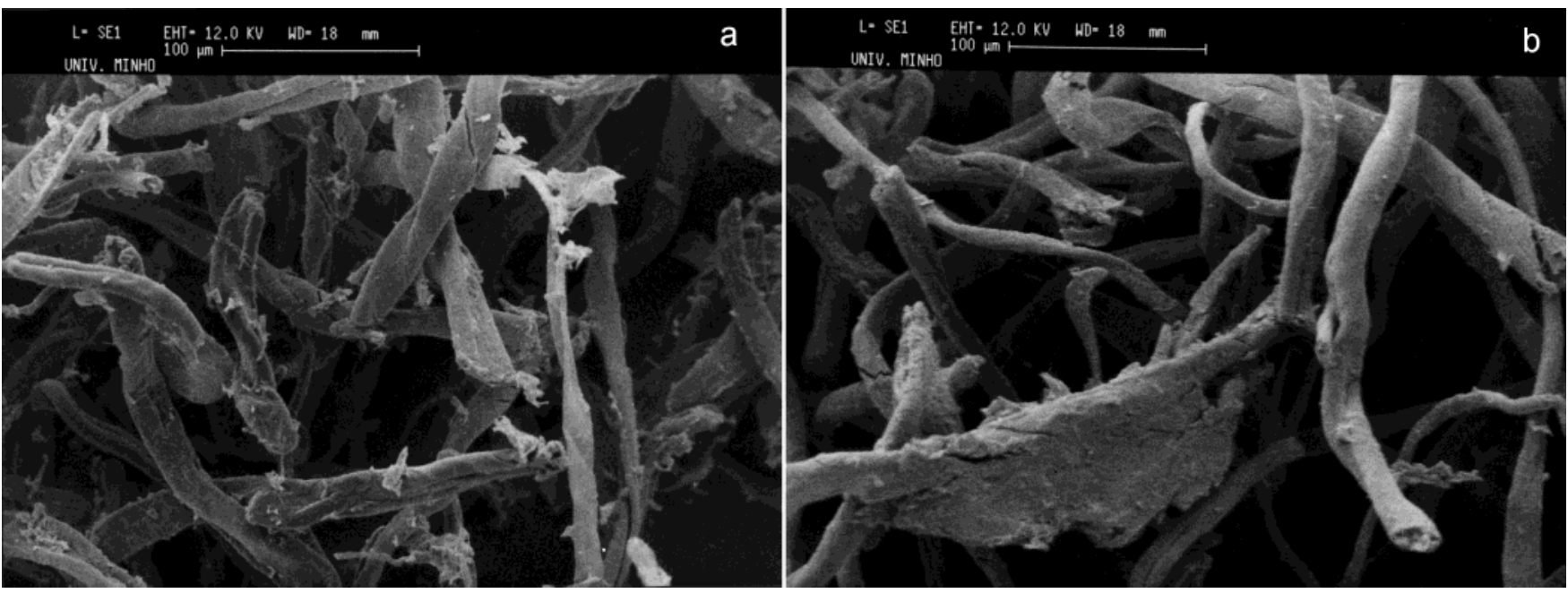

Figure 4. SEM images of CF 11 fibers treated with (a) and without (b) CBD.

Table 5. Specific Surface Free Energy $\left(-\Delta G^{A B}{ }_{A}, k J / m o l\right)$ for the Interaction with Different Probes

\begin{tabular}{lccccccc}
\hline & \multicolumn{3}{c}{ CF 11 with CBD } & & \multicolumn{3}{c}{ CF 11 without CBD } \\
\cline { 2 - 4 } \cline { 6 - 8 } \multicolumn{1}{c}{ probes } & $35^{\circ} \mathrm{C}$ & $42{ }^{\circ} \mathrm{C}$ & $50^{\circ} \mathrm{C}$ & & $35^{\circ} \mathrm{C}$ & $42{ }^{\circ} \mathrm{C}$ & $50{ }^{\circ} \mathrm{C}$ \\
\hline chloroform & 1.63 & 1.57 & 1.40 & & 1.85 & 1.59 & 1.62 \\
THF & 7.39 & 7.07 & 6.51 & & 8.06 & 7.60 & 7.29 \\
diethyl ether & 6.12 & 5.77 & 5.26 & & 7.02 & 6.41 & 6.17 \\
acetone & 9.97 & 9.67 & 9.01 & & 11.4 & 10.9 & 10.6 \\
ethyl acetate & 8.57 & 8.23 & 7.72 & & 9.64 & 9.26 & 9.16
\end{tabular}

explained by the occultation of hydroxyl groups on the fibers surface, thus lowering their acidic character.

The values for the acid and basic numbers $\left(K_{A}\right.$ and $K_{D}$, respectively) werealso calculated but they arestatistically not significant, mostly because of error propagation, which masks the differences observed in Table5. Therefore, they are not presented in this work.

Xiao et al. ${ }^{32}$ reported a reduction in the crystallinity index of a cellulose treated with a fungal endoglucanase CBD. In the present work, the crystallinity index $(92.0 \%$ and $91.9 \%$, with and without CBD, respectively) was not modified by CBDs, in agreement with the $\gamma^{D_{s}}$ results; as a matter of fact, a reduction in crystallinity would probably imply a modification of the $\gamma^{D_{S}}$ value. An interesting morphological modification was observed by SEM (Figure 4). Fiber agglomerates disappeared after the CBD treatment that simultaneously led to the appearance of small particles all over the fibers. Apparently, CBDs disrupt the aggregates that upon drying become spread on the 715.

(32) Xiao, Z.; Gao, P.; Qu, Y.; Wang, T. Biotech. Lett. 2001, 23, 711- surface of thelarger fibers. Such a disintegration process may be associated to an increase in surface area, as suggested previously. This effect must be interpreted as an interfacial phenomenon. Indeed, IGC does not reveal a dramatic modification of thesurface properties following the CBD treatment, besides the reduction in the acidic character. Then, the CBD treatment possibly reduces the interfiber interaction (deseggregating the fibers, as observed by SEM), by means of steric and hydrophobic effects.

\section{Conclusions}

The IGC technique was used to detect surface energy modification following CBDs adsorption onto cellulose fibers. A reduction of the acid character of the fibers was detected and confirmed by ESCA analysis. No major modification of the dispersive component of the surface energy was detected, although the retention volume of neutral probes was slightly increased. This increase may be due to free hydrophobic amino acids present in the adsorbed CBDs or to an increase in the fibers surface area. CBDs appear to break down aggl omerates presented between thefibers, but no modification of the crystallinity index was noticed. The modification of fiber properties by CBDs, detected in previous work, may also have an important contribution associated to steric or hydrophobic effects that were not assessed in these experiments.

Acknowledgment. Ricardo Pinto was supported by Fundação para a Ciência e a Tecnologia (FCT) grant SFRH/BD/6934/2001.

LA035611U 